\title{
Mechanical Strength and Thermal Conductivity of Low-Porosity Gypsum Plates
}

\author{
Conceição de Maria Pinheiro Correia*, Milton Ferreira de Souza
}

\author{
Department of Physics and Materials Science, Institute of Physics of São Carlos, USP, \\ Av. Trabalhador Sancarlense, 400, Centre, \\ CP 369, 13560-970 Sao Carlos - SP, Brazil
}

Received: October 3, 2008; Revised: February 23, 2009

\begin{abstract}
The thermal conductivity and mechanical strength of gypsum and gypsum-cellulose plates made from commercial plaster by a new process have been measured. The gypsum parts made by the new process, 'novogesso', have high mechanical strength and low porosity. The gypsum strength derives from both the high aspect ratio of the gypsum crystals and the strong adhesion among them by nano-flat layers of confined water, which behaves as supercooled water. Another contribution to the strength comes from the nano-flatness of the lateral surfaces of the gypsum single crystals. The bending and compression strengths, $\sigma_{\mathrm{B}}$ and $\sigma_{c}$, of gypsum plates prepared by this new technique can be as high as 30 and $100 \mathrm{MPa}$, respectively. The way gypsum plates have been assembled as well as their low thermal conductivity allowed for the construction of a low-cost experimental house with thermal and acoustic comfort.
\end{abstract}

Keywords: thermal conductivity, high strength, gypsum, cellulose, comfort

\section{Introduction}

\subsection{Gypsum}

Gypsum, $\mathrm{DH}, \mathrm{SO}_{4} \mathrm{Ca} .2 \mathrm{H}_{2} \mathrm{O}$ crystals are derived from plaster, $\mathrm{HH}, \mathrm{SO}_{4} \mathrm{Ca} .1 / 2 \mathrm{H}_{2} \mathrm{O}$ crystals by hydration according to the chemical equation:

$$
2.0\left(\mathrm{SO}_{4} \mathrm{Ca} .1 / 2 \mathrm{H}_{2} \mathrm{O}\right)+3.0\left(\mathrm{H}_{2} \mathrm{O}\right) \rightarrow 2.0\left(\mathrm{SO}_{4} \mathrm{Ca} .2 \mathrm{H}_{2} \mathrm{O}\right)
$$

Gypsum crystals grow through the HH dissolution in water and the DH crystals seed and grow. Such a process was already proposed by Le Chatelier ${ }^{1}$ in 1883 , therefore it has always been thought that an excess of water would be needed to help the dissolution of plaster. The minimum mass ratio between water and the $\mathrm{HH}, \mathrm{W} / \mathrm{HH}$, required for the full hydration of the $\mathrm{HH}$ mass, as given by the above equation, is 0.186 , nearly $20 \%$ of water relative to the $\mathrm{HH}$ mass. Such a W/HH ratio results in a humid $\mathrm{HH}$ powder, which is hard to hydrate. For many centuries gypsum pieces have been made using $\mathrm{W} / \mathrm{HH}$ ratios close to 1.0 , which produce low-viscosity water-plaster suspensions that help the conformation of gypsum. The density, mechanical strength and water resistance of those gypsum parts is low. However comparing the parts made of gypsum with the cement-made ones, gypsum parts cost less, are fully recyclable and the preparation of their hemihydrate consumes much less energy than cement. Brazil has two sources of gypsum: one of mineral origin and phosphogypsum, derived from the phosphate production.

The thermal and mechanical properties of materials for civil engineering applications are of great importance for the house's performance. The thermal conductivity of materials has a direct effect on both the construction project and the comfort of the house environment. The design of the experimental house made of gypsum considered sustainability throughout the planning and integration of the components made with the aid of a new constructive technology, taking into account the best use of natural resources. The walls were built by fixing high-strength gypsum plates, $\left(60.0 \times 120.0 \times 1.5 \mathrm{~cm}^{3}\right)$, using the new "novogesso' technology. The plates made of either mineral gypsum or phosphogypsum are fully recyclable. The development of the 'novogesso' process ${ }^{2}$ by an innovative technology has allowed for the preparation of potentially low-cost components, such as floor tiles, beams, columns, bricks and internal and external wall plates made of high mechanical strength and low porosity gypsum. It is well known that gypsum plates for external use made by the usual processes do not survive the action of liquid water during the raining seasons. The application of the gypsum plates made by the 'novogesso' process in the external walls of the experimental house was the main motivation for its construction. This paper presents a new process for the preparation of high-strength and low-porosity gypsum plates together with their mechanical strength and thermal conductivity.

\section{Materials and Methods}

\section{1. 'Novogesso'}

In common practice gypsum parts are made from low-viscosity suspensions usually with W/HH close to 1.0. For these high W/HH ratios, nearly $80 \%$ of the mixed water must be evaporated after the hydration reaction has been completed, turning the common gypsum bodies porous and, therefore, weak. The 'novogesso' process uses the $\mathrm{W} / \mathrm{HH}$ relation close to $20 \%$. Water is sprayed on the plaster powder while mixing, resulting in a uniformly humidified powder that is immediately compressed and extracted from the steel mold. In such a process liquid water is sent to the pores of the compacted plaster powder. As the major part of the liquid water is restricted to the internal larger pores, the hydration reaction occurs mainly in these pores, while in the traditional process it occurs everywhere. Therefore, in comparison to the traditional process where the $\mathrm{W} / \mathrm{HH}$ is five times higher, the gypsum crystals produced by the 'Novogesso' process are 
in a smaller number, but they are much larger. The micro-structure of a high-strength gypsum plate is given in Figure 1.

Gypsum bodies produced by this new process have high density and are mechanically stronger. For gypsum plates having $1.6 \mathrm{~g} . \mathrm{cm}^{-3}$ density, their strengths to bending and compression were found to be as high as 15.0 and 40.0 MPa, respectively. The new process can produce denser and stronger bodies by adjusting the compacting pressure. The 'novogesso' process works well with plaster from mineral or industrial origin (phosphogypsum) ${ }^{3}$. An additional advantage of the low $\mathrm{W} / \mathrm{HH}$ ratio comes from the small quantity of water that needs to be evaporated after the hydration reaction. Also, the much shorter time needed for the gypsum plates to become strong reduces costs and production time. The most known and used gypsum component for house building, the dry wall plate, is made of two plates of strong paper separated by a thick layer of gypsum of low density, low resistance to compression and, therefore absorbs water.

An additional requirement to produce high-strength gypsum parts is the development of adhesion forces among the gypsum crystals (there is no gypsum in the amorphous phase). For the first time it has been found that capillary pressure does not contribute to adhesion among the gypsum crystals - the water capillary pressures decrease the mechanical strength of gypsum. Water layers thinner than $2.0 \mathrm{~nm}$ develop strong adhesion among the gypsum crystals. In the literature such nanometric layers are known as confined water ${ }^{4,5}$. Confined water behaves as glasses, like the supercooled water ${ }^{6,7}$, and, therefore, suffers the weak $\rightarrow$ strong transformation. For confined water the characteristic temperature for this transformation is $-45^{\circ} \mathrm{C}$. To confirm that the gypsum crystals are bonded by confined water, we have measured the strength to bending, $\sigma_{\mathrm{B}}$, of gypsum plates at temperatures above and below $-45^{\circ} \mathrm{C}$.

Two series of gypsum plates, $\mathrm{A}$ and $\mathrm{B}$, have been prepared to study the effect of temperature on the mechanical strength of 'Novogesso'. Both were initially fully dried at $60{ }^{\circ} \mathrm{C}$ at a constant weight. Series A was prepared for the mechanical measurements as it was (black in Figure 2). Series B was soaked in water for 1.0 hour before measurements (gray in Figure 2).

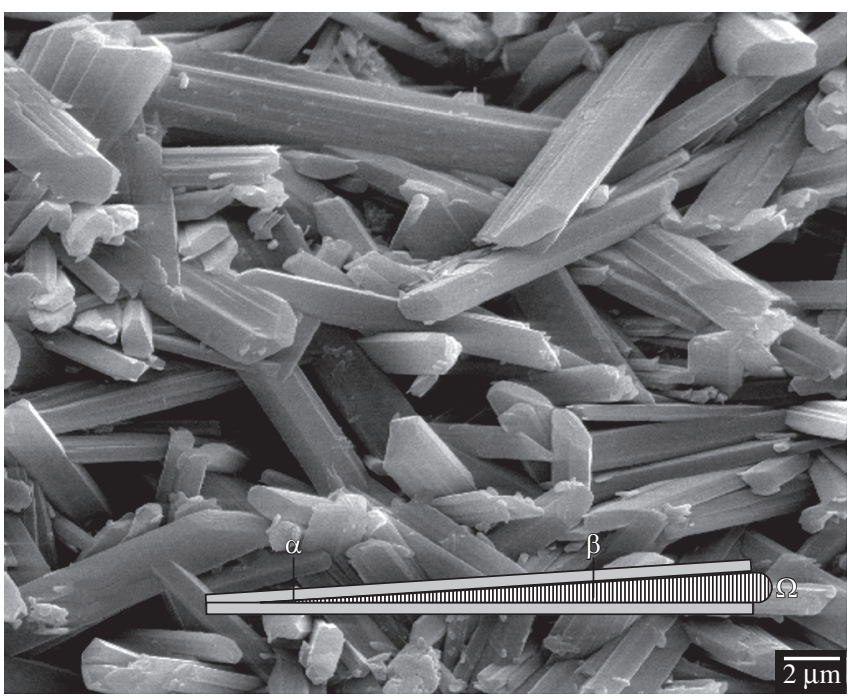

Figure 1. Microstructure of the fractured surface of a high-strength gypsum plate. The insert is for two crystals distant from each other by the $\Omega$ angle. The thick $\beta$ region is for bulk water and $\alpha$ region is for confined water. The $\beta$ region becomes progressively smaller under drying. The confined water remains as it has a lower vapor pressure. Gypsum crystal surfaces are flat, as expected from whisker crystals.
Therefore, the A series had a higher volume of confined water than the B series, whose crystals are slightly apart due to the capillarity pressure of water. According to the usual behavior of confined water, during cooling toward $-45^{\circ} \mathrm{C}$, the confined water must progressively become mechanically stronger and less dense. As Figure 2 shows, the lower strength of the humid plates increase under cooling, as expected. The initial higher strength of the A series of plates is in accordance with their higher volume of confined water. However, a further cooling of the A series of plates suffers a substantial decrease in strength from 25.0 to $8.0 \mathrm{MPa}$, before reaching $-45^{\circ} \mathrm{C}$, indicating the expansion of the volume of confined water causes the irreversible breaking of the gypsum crystals. This behavior was found to be highly reproducible and demonstrates that adhesion among the gypsum crystals is made by confined water, as expected ${ }^{6,7}$.

Confined water is currently a large and competitive research field in materials science and biology. We have found that confined water has a lower vapor pressure than bulk water, therefore the gypsum strength remains high even in hot environments ${ }^{8}$. Denser and mechanically stable gypsum pieces with higher mechanical resistance are obtained with the help of confined water, adhesion strength and the high aspect ratio of gypsum single crystals (whiskers). The high level of the mechanical properties of 'Novogesso' makes it possible to replace cement in some applications, such as floors and internal and external walls.

\subsection{Cellulose}

Cellulose, the most abundant organic substance on earth, is a natural hydrophilic polymer. These properties have motivated researches to find applications for the cellulose fiber in reinforced materials. The cellulose fibers made from eucalyptus trees for the paper industry have 2.0-3.0 mm of length and diameter close to $20 \mu$, limit imposed by the refining technology. Cellulose fibers are made by the aggregation of cellulose nanofibrils through hydrogen bonds. The opening of fibers to produce cellulose nanofibrils requires the application of costly procedures - steam explosion, micro fluidizers - since the bond energy of the intra and inter hydrogen bridges is high and dependent on the structural configuration of the $(\alpha, \beta)$ cellulose 9 . Once a lowcost technology has been developed, the nanocellulose fibrils will be used as new reinforcing fibers of extremely high mechanical resistance. When mixed to plaster powders, those nanofibers will produce high strength and high resistance to crack propagation composites.

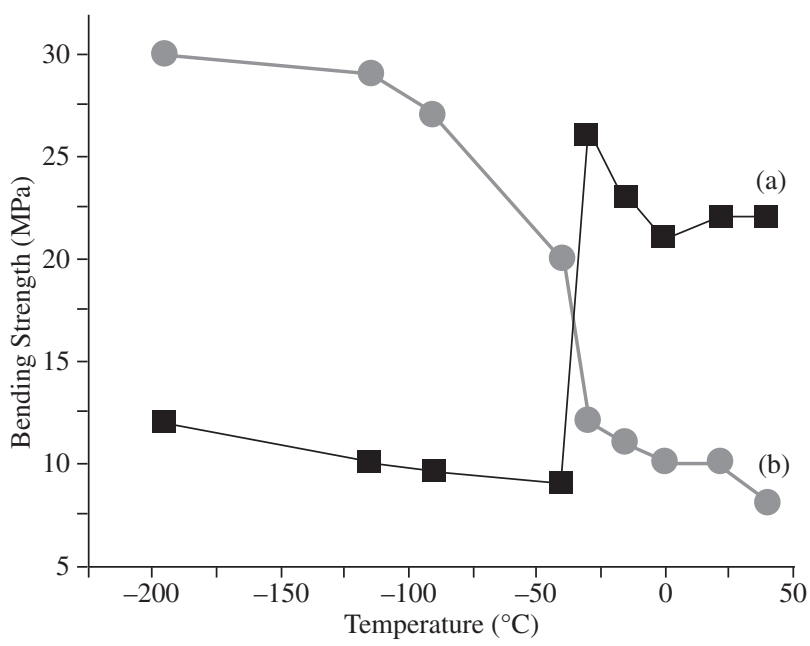

Figure 2. Temperature dependence of the bending strength of gypsum plates $\left(7.0 \times 3.0 \times 1.3 \mathrm{~cm}^{3}\right)$ : black (a), for fully dried plates at $60{ }^{\circ} \mathrm{C}$; gray for rehumidified plates (b). 
The mixing of moderate concentrations of common paper cellulose ( $\approx 3.0 \mathrm{~mm}$ length and $20 \mu \mathrm{m}$ diameter) contributes to decreasing the density and the bending strength among the gypsum crystals. The cellulose concentration must compromise to keep part of the new gypsum strength with a decrease in the thermal conductivity. In the near future cellulose nanofibers distributed among the gypsum crystals will result in composites with low thermal conductivity and high mechanical strength.

\subsection{Measuring methods}

\subsubsection{Mechanical strength}

Density was calculated from the dimensions and weight of each plate with the help of a micrometer and an analytical SHIMADZU ${ }^{\circledR}$ balance model AY 220. The mechanical strength was measured with the help of an assay machine EMIC model DL 2000 to which a chamber has been attached, allowing for measurements from $100{ }^{\circ} \mathrm{C}$ to LNT.

\subsubsection{Thermal conductivity}

The thermal conductivity of the wall plates was measured by the hot wire technique ${ }^{10}$, a direct absolute and non-stationary method that measures thermal conductivity in a wide range of temperatures. The hot wire method is a low-cost experimental technique suitable to industrial usage ${ }^{11}$.

The basic theoretical knowledge consists in taking the hot wire as an ideal and infinitely long and thin source of heat, which is surrounded by a material whose thermal conductivity one aims to determine. When an electrical current flows through the wire, a constant amount of heat per unit of time and length is released by the wire and spreads through the material ${ }^{12}$. The conductivity is then determined from the measurement of the rate of the temperature increase of the material at point $\mathrm{p}$ and distance $\mathrm{r}$, from the hot wire. The thermal conductivity is given by Equation ${ }^{13}$,

$$
K=-\frac{q^{\prime}}{4 \pi T} E_{i}\left[\frac{\left(-\rho c r^{2}\right)}{4 K t}\right]
$$

where:

$\mathrm{K}=$ thermal conductivity $(\mathrm{W} / \mathrm{m} \mathrm{k})$

q' = density linear power $\left(\mathrm{W} . \mathrm{m}^{-1}\right)$

$\mathrm{T}=$ excess of temperature in relation to the original reference temperature $(\mathrm{K})$

$\rho=$ density of the material $\left(\mathrm{kg} \cdot \mathrm{m}^{-3}\right)$

$\mathrm{c}=$ specific heat of the material $(\mathrm{J} / \mathrm{kg} \mathrm{K})$

$\mathrm{r}=$ radial distance from the hot wire $(\mathrm{m})$

$\mathrm{t}=$ time, counting from the beginning of the heat release $(\mathrm{s})$

$\mathrm{E}_{\mathrm{i}}=$ Integral exponential function

The effect of both density and cellulose concentration on the thermal conductivity of the 'novogesso' plates was measured. The plates of $\left(20.0 \times 20.0 \times 1.5 \mathrm{~cm}^{3}\right)$ were stockpiled like a sandwich. Two grooves were made in the plate at the center of the stockpile, a longitudinal one at the center of the plate for the hot wire, and a transversal one in the middle of the plate, $1.5 \mathrm{~cm}$ far from the hot wire to measure the temperature with the aid of a thermocouple. The grooves' depths are equal to the hot wire's and thermocouple's thicknesses and are filled with a water paste made from the same material of the plates. The surfaces of these plates were prepared to provide the best thermal contact among the plates. Experimental data, including room temperature, were acquired by a computer for further processing.

\section{Results and Discussions}

\subsection{Strength and density of the gypsum plates}

The effect of the compaction pressure for a fixed time of 60 seconds on the mechanical strength and density of the gypsum plates made from $\mathrm{HH} \beta$ plaster of mineral origin, according to the 'novogesso' method, are given in Table 1. As density increases, the distance among the gypsum crystals decreases, i.e., the crystals are closer, allowing for the development of adhesion forces through nano-layers of confined water. The increase in density shows less porous and stronger gypsum bodies. Therefore, these results show that high mechanical strength and density can be obtained by the application of higher compaction pressures.

The effect of cellulose fibers addition on the mechanical strength of gypsum-cellulose composites is given in Table 2. Cellulose fibers are obtained from Eucalyptus wood, the same wood used for paper making $(\approx 20 \mu \mathrm{m}$ diameter and 2.0 to $3.0 \mathrm{~mm}$ length) and have been

Table 1. Dependence of the density and strength on the compaction pressure ( 60 seconds) of the 'Novogesso' plates $\left(7.0 \times 3.0 \times 1.3 \mathrm{~cm}^{3}\right)$ made by the hydration of pure $\mathrm{HH} \beta$ plaster. For each compaction pressure, 10 plates have been prepared and measured.

\begin{tabular}{|c|c|c|c|}
\hline Compaction pressure $(\mathrm{MPa})$ & Density $\rho\left(\mathrm{g} / \mathrm{cm}^{3}\right)$ & Bending strength $\sigma_{\mathrm{B}}(\mathrm{MPa})$ & Compression strength $\sigma_{\mathrm{c}}(\mathrm{MPa})$ \\
\hline 0.00 & $1.10 \pm 0.05$ & $3.0 \pm 1$ & $10.0 \pm 3$ \\
\hline 0.50 & $1.55 \pm 0.05$ & $10.0 \pm 1$ & $30.0 \pm 3$ \\
\hline 1.00 & $1.68 \pm 0.02$ & $11.0 \pm 1$ & $33.0 \pm 2$ \\
\hline 1.50 & $1.73 \pm 0,02$ & $12.0 \pm 1$ & $35.0 \pm 3$ \\
\hline 2.00 & $1.80 \pm 0.02$ & $12.0 \pm 1$ & $38.0 \pm 4$ \\
\hline 3.00 & $1.85 \pm 0.02$ & $13.0 \pm 1$ & $40.0 \pm 3$ \\
\hline 5.00 & $1.90 \pm 0.01$ & $15.0 \pm 1$ & $50.0 \pm 3$ \\
\hline 8.00 & $1.94 \pm 0.01$ & $25.0 \pm 1$ & $80.0 \pm 3$ \\
\hline 10.00 & $1.98 \pm 0.01$ & $31.0 \pm 1$ & $101.0 \pm 4$ \\
\hline
\end{tabular}

Table 2. Density and mechanical strength of gypsum-cellulose composite plates made by compaction at $20 \mathrm{MPa}$ and dried at $60{ }^{\circ} \mathrm{C}$ for 24 hours. Cellulose $\%$ relative to $100 \mathrm{~g}$ of $\mathrm{HH} \beta$.

\begin{tabular}{ccccc}
\hline Celullose $(\%)$ & Water $(\mathrm{g})$ & Density $\rho\left(\mathrm{g} . \mathrm{cm}^{-3}\right)$ & Bending strength, $\sigma_{\mathrm{B}}(\mathrm{MPa})$ & Compression strength, $\sigma_{\mathrm{C}}(\mathrm{MPa})$ \\
\hline 1.0 & 21 & 1.9 & 30.0 & 65.0 \\
10.0 & 25 & 1.5 & 30.0 & 55.0 \\
20.0 & 35 & 1.4 & 25.0 & 38.0 \\
\hline
\end{tabular}


well mixed with the dry $\mathrm{HH}$ powder. These results have shown that both density and mechanical strength decrease while the cellulose concentration increases. The results can be understood considering that the cellulose fibers' diameter is very large $(20 \mu \mathrm{m})$ in comparison to the thickness of the confined water $(2,000 \mu \mathrm{m})$, therefore adhesion by confined water is strongly decreased. It can be expected that cellulose nanofibers (cellulose whiskers) would have increased the strength of the gypsum plates. High-strength gypsum cellulose composites can be prepared by increasing the compaction pressure, however the costs for their production increase.

Comparison among the mechanical properties of 'novogesso' blocks with cement and gypsum made by other processes are given in Table 3.

\subsection{Thermal conductivity of gypsum plates}

The experimental data of the temperature measurement given in Figure 3 are used in Equation (2). According to this equation, the conductivity is determined from the measurement of the rate of temperature increase. The slope of a plot log time $\mathrm{x}$ temperature provides the thermal conductivity behavior. The simulation and the experimental data produce the same behavior, therefore the experimental set-up made for the determination of the thermal conductivity was adequate to produce reliable data.

The thermal conductivity of gypsum plates made only of gypsum is given in Figure 4, curve d. A comparison among the a, b and c curves shows that in the cellulose gypsum-composites, the thermal conductivity decreases when the cellulose concentration in the composite increases. It clearly shows that the thermal conductivity of the pure gypsum plates is much higher than that of the composites.

The effect of cellulose concentration on the gypsum-cellulose composites, Table 4, clearly shows that, by increasing the cellulose fibers concentration, the density and the thermal conductivity of the gypsum-cellulose plates systematically decrease. The percentage decrease of the thermal conductivity is quite significant: nearly $50 \%$ in comparison with pure gypsum plates. High-strength gypsumcellulose composites can be further improved by using cellulose nanofibers. Due to the high hydrophilicity and strength of cellulose and gypsum whiskers, the gypsum-cellulose composites may become

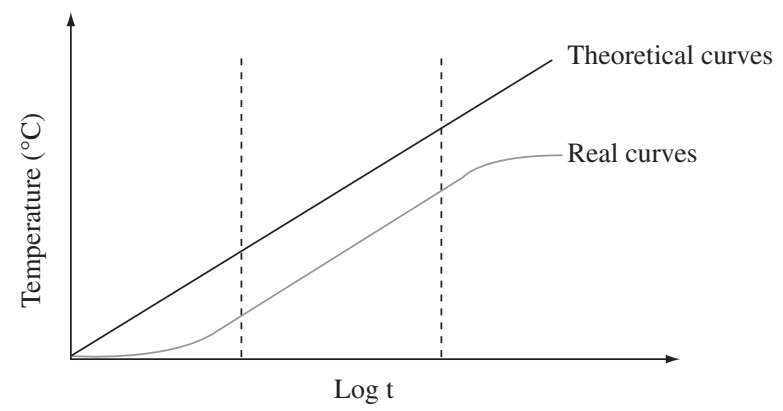

Figure 3. Theoretical and real curves of temperature as a function of time. a very competitive material for house construction in a near future. The thermal insulation between the external and internal walls was achieved by letting the air flow freely between them and the ceiling and roof to the outside of the house. In addition, insulation layers of soft cotton made from residues of cloth industry were used. Other factors, such as location on the ground and superficial treatment of the walls also contributed to achieving the desired environmental conditions. The temperature inside the experimental house was found to range between 25 and $29{ }^{\circ} \mathrm{C}$ in hotter months, and 18 to $22{ }^{\circ} \mathrm{C}$ in colder seasons, without the aid of heating or cooling devices.

\section{Conclusions}

The process to prepare a high-strength low-porosity material 'Novogesso' has been described and characterized. Gypsum plates made using the 'Novogesso' are strong enough to be considered a structural material for use in internal and external walls. By associat-

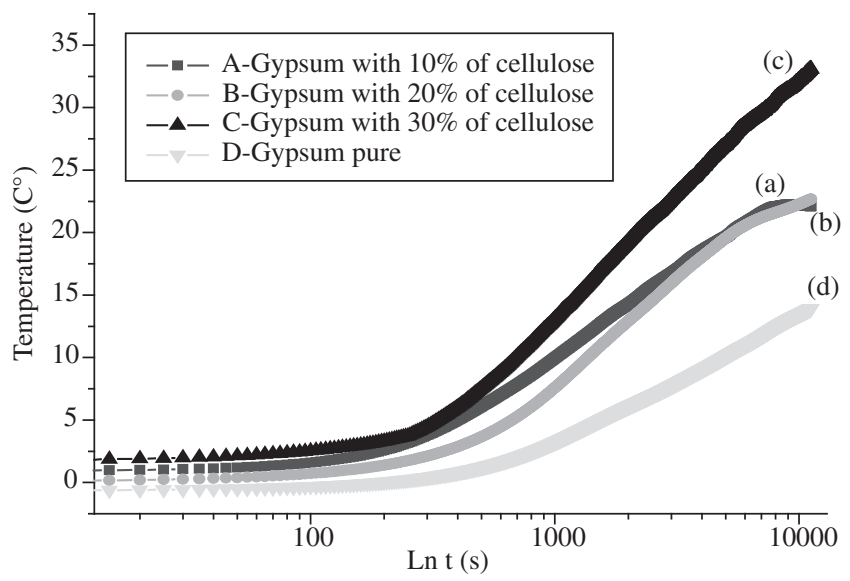

Figure 4. Time dependence of the thermocouple temperature during the measurement of the thermal conductivity of gypsum - cellulose composites.

Table 4. Thermal conductivity and density of the gypsum-cellulose composites.

\begin{tabular}{cccc}
\hline Cellulose (\%) & $\begin{array}{c}\text { Density } \\
\left({\left.\mathrm{g} . \mathrm{cm}^{-3}\right)}\right.\end{array}$ & $\begin{array}{c}\text { Thermal } \\
\text { conductivity } \\
\left(\mathrm{W} . \mathrm{mK}^{-1}\right)\end{array}$ & $\begin{array}{c}\text { Conductivity } \\
\text { loss }(\%)\end{array}$ \\
\hline $0.0^{*}$ & 0.75 & 0.35 & - \\
0.0 & 1.94 & $0.75 \pm 0.02$ & 0.00 \\
10.0 & 1.50 & $0.61 \pm 0.03$ & 18.7 \\
20.0 & 1.33 & $0.45 \pm 0.01$ & 40.0 \\
30.0 & 1.18 & $0.40 \pm 0.03$ & 46.7 \\
\hline
\end{tabular}

* Gypsum plates produced by the method of suspension.

Table 3. Comparison of the mechanical strengths of gypsum products (Source: Sindugesso/ Pernambuco, Brasil).

\begin{tabular}{lcc}
\hline \multicolumn{1}{c}{ Products } & Bending strength, $\sigma_{\mathrm{B}}(\mathrm{MPa})$ & Compression strength, $\sigma_{\mathrm{C}}(\mathrm{MPa})$ \\
\hline Gypsum blocks* & $2.0-4.0$ & $4.5-5.5$ \\
Gypsum plates* & $2.0-4.0$ & - \\
Auto-leveling gypsum paste & 3.0 & 20.0 \\
'Novogesso' & 40.0 & 75.0 \\
High-strength cement** & 6.0 & 115.0 \\
\hline
\end{tabular}

*Made using the $\mathrm{W} / \mathrm{HH}=1.0$; and **Made by spraying $15 \%$ of water, and compressed as the gypsum and at the same age, 7 days. 
ing gypsum and cellulose fibers, cellulose-gypsum composites can become a light and low thermal conducting material for future house constructions. According to the values of the thermal conductivity and mechanical strength, it is possible to conclude that 'novogesso' plates can already be considered a constructive element that strongly contributes to thermal comfort. The intensive research on cellulose currently being developed around the world will make low-cost cellulose whiskers available in the near future, allowing for the future industrial production of high-quality gypsum-cellulose composites. The addition of cellulose whiskers will keep the mechanical resistance high.

\section{Acknowledgements}

The authors acknowledge FINEP and FAPESP for the support to INOVAMAT Ltda, a research and development private company that allowed for the building of the experimental house taking into account the sustainability criteria, low-cost building and comfort for the family life. The stay of C.M.A. Correia in São Carlos was possible by means of a CNPq scholarship.

\section{References}

1. Le Chatelier, H. Comptes Rendus Hébdomadaires dês Séances de l'Académie dês Sciences, Paris. 1883; 96:715.

2. Souza MF, Rosseto HL, Kanno WM. Gesso e compósitos de alta resistência mecânica e baixa permeabilidade e seu processo de fabricação. Patente Industrial n. 0303814-9, 2003 setembro 09.

3. Souza MF. Fosfogesso e suas misturas com gesso mineral: matéria prima para produção de peças de gesso e métodos de preparação. Patente Industrial n. 002931. 2004 janeiro 09.
4. Belissant-Funel MC, Chen SH, Zanotti JM. Single particle dynamics of water molecules in confined space. Physical Review E. 1995; 51(5):4558-4569.

5. Starr FW, Nielsen JK, Stanley HE. Fast and slow dynamics of hydrogen bonds in liquid water. Physical Review Letters. 1999; 82(11): 2294-2297.

6. Debenedetti PG, Stillinger FH. Supercooled liquids and the glass transition. Nature. 2001; 410(6825):259-267.

7. Speed CR, Angell CA. Isothermal compressibility of supercooled water and evidence for a thermodynamic singularity at $-45 \mathrm{oC}$. Journal of Chemical Physics. 1976; 65(3):851-858.

8. Angell CA. Supercooled water: approaching the limits. Nature. 1998; 331(6153):206-207.

9. O'Sullivan AC. Cellulose: the structure slowly unravels. Cellulose. 1997; 4(3):173-207.

10. Staff PRE. Essai des matières premières et produits céramiques. Détermination de la conductivité thermique jusquu'à 1600 par la méthode du fil chaud. Conductivité thermique $\leq 25 \mathrm{Wm}^{-1} \mathrm{~K}^{-1}$. Méthode en parallèle. Bulletin de la Société Française Cé Ramique. 1980; 126(1):15-24.

11. Davis WR, Moore F, Downs AM. Hot wire method for the determination of thermal conductivity: castables and modifications to the standard method. Transactions and Journal of the British Ceramic Society. 1980; 79(6):158-166

12. Santos WN, Cintra FJS. Efeito da temperatura na condutividade térmica e calor específico de materiais cerâmicos, determinados simultaneamente pelo método do fio quente paralelo. Cerâmica. 1987; 33(212):198-202.

13. Carslaw HS, Jaeger JC. Conduction of heat in solids. Oxford: Oxford University Pres; 1959. 